\title{
Tibito Tephra, Taim Tudak and the Impact of Thin Tephra Falls
}

\author{
Russell Blong
}

\section{Introduction}

The cataclysmic eruption of Long Island that produced Tibito Tephra probably occurred in the decade of the AD 1660s. The eruption, in terms of the volume of tephra produced, was equal in size to the eruption of Krakatau in 1883, devastating Long Island and spreading the tephra across the north coast and highlands of Papua New Guinea (PNG). Some 85,000 $\mathrm{km}^{2}$ of land area were covered by up to $10 \mathrm{~mm}$ of ash. Despite the size of the eruption, one of the 10 largest anywhere in the world in the last thousand years, it appears not to have been recorded anywhere in written form.

Dozens of groups of people across PNG retain stories about a taim tudak, when darkness prevailed for several days and sand or dust fell from the sky, ruining crops, killing birds and animals, collapsing some house roofs and killing a few people (Fig. 8.1). The available legends are presented in full in Blong (1979b) and an extended interpretation can be found in Blong (1982). Only a few aspects of the stories are considered here. The Time of Darkness story and its variants are summarised and comparisons made with what we know of the effects of modern tephra falls. In most aspects, the taim tudak stories are essentially accurate accounts of the consequences of a thin tephra fall, though there are aspects of some accounts that appear exaggerated or erroneous. The chapter ends by outlining the likely outcomes if a similar fall of tephra were to occur today.

In total, about a hundred versions of the taim tudak legend have been collected by (mainly) anthropologists and missionaries. At least 56 of these versions come from the area where we can be confident that Tibito Tephra is the uppermost tephra and, therefore, the almost certain inspiration for the taim tudak story (Fig. 8.1) (Blong 1979b, 1982). While we might surmise that there have been minor dustings of tephra, of only a couple of millimetres or less, subsequent to the fall of Tibito Tephra in at least some of these areas, there is no current stratigraphic or historical evidence that such minor falls have occurred in the last few hundred years. Most of the accounts of the taim tudak were collected more than 300 years after Tibito Tephra fell.

Some of the legends report the fall of more than one tephra. Minor dustings might be included here, but the Kuk investigations reveal the presence of many older thin tephras that fell during the last 14,000 years or so. While we have no direct evidence of the impact of these earlier falls, we can assume that they produced rather similar consequences to those described for Tibito Tephra and contained in the taim tudak stories. 


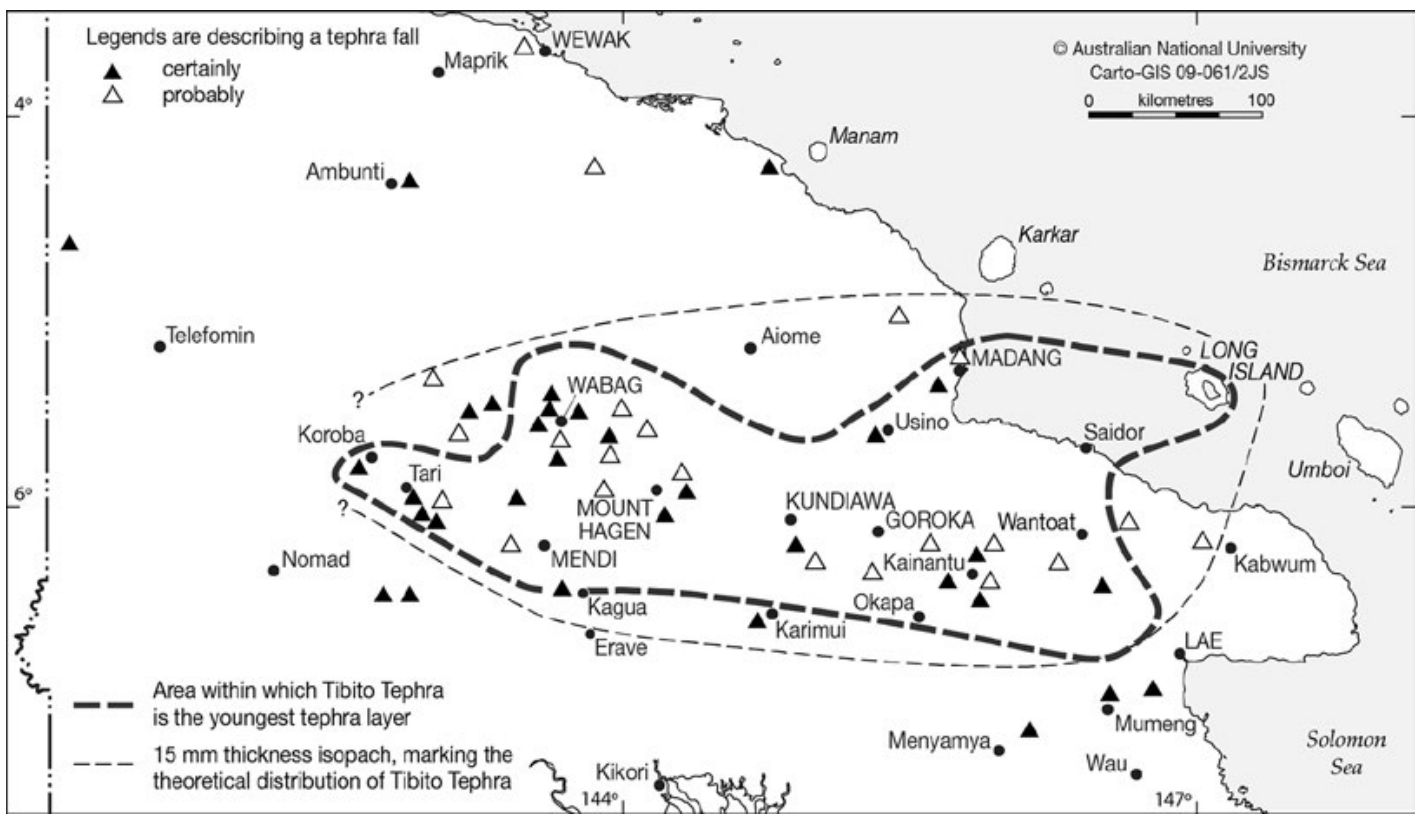

Figure 8.1 Location of Time of Darkness legends, shown in relation to the area within which Tibito is the youngest tephra.

Source: Drawing by Jennifer Sheehan, CartoGIS Services, College of Asia and the Pacific, ANU, based on Blong (1982: Figs 35 and 31), reproduced with permission.

While the impacts of tephra falls on other aspects of everyday life are examined, this chapter focuses on the impact of thin tephra falls on plant resources, animals and insects. In reality the effects cannot be separated - a food resource might flourish because of the extermination of an insect predator, or it might be decimated because a pollinating insect comes close to local (and temporary) extinction.

It is important to recognise that we know too little about the effects of tephra falls on plants, animals, buildings, people and societies in the PNG region or, for that matter, anywhere in the world. We must also recognise that perceptions are just as important as realities, confounding what we think we know. For example, about two weeks after a fall of less than $10 \mathrm{~mm}$ of tephra on Karkar Island in 1979, subsistence farmers reported taro tubers were rotting in the ground as a result (personal fieldwork observation). Local agricultural officers believed that taro blight, unconnected with the eruption, was the cause of the decay. Perception and reality are intertwined in at least some of what follows.

\section{The taim tudak legend}

As implied by Figure 8.1, there are numerous versions of the taim tudak legend. The one given below was collected in the 1930s by the German Lutheran missionary Georg F. Vicedom (Vicedom and Tischner 1943-48, vol.1: 91) from Melpa-speaking inhabitants of the upper Wahgi Valley around the present Mount Hagen town, to whom the Kuk people are related and who speak the same language. Its early collection date may be the reason why it is less affected by the mixing of different events that is evident in later versions. The translation of Vicedom's German text is by Andrew Strathern (Vicedom 1977: 67):

Once upon a time, in olden days, men saw to the south the whole land was covered with dark clouds. A storm was on its way and there was a rustling and a whistling in the air. They asked what this meant, and heard that it was raining ashes in those parts, so that the people could not go out 
to dig up their food crops. So they themselves went out and gathered in supplies. The ash-storm reached them and they had to stay inside their houses for four or five nights. By this time they were either terribly hungry or else they actually did starve to death. They were badly shocked by the event and were sure they would all be annihilated and that their spirits had deserted them, although they continued to pray. Gradually over a two day period it grew light again, till they were able to emerge and saw their crops and fields were ruined. They were in great need, as their stores were finished and they had to plant new crops while they were still hungry. After a month nearly all of them died. A few remained and through time increased again. The plants we grow were handed down to us from those survivors. People today do not know that the ash-storms once took place. Men have increased again and it is said that a new race of men lives.

\section{Characteristics of the tephra fall}

Almost all the taim tudak legends refer to the fall of ash or dust or sand. Four accounts describe falling stones and one of these includes falling trees (Blong 1979b, 1982). Of the 43 accounts that contain some information about the thickness of the tephra fall, 36 describe it as only a dusting, or thick enough to cover plants, or thick enough to break down houses and trees. Most of the seven describing thicker falls occur in the western part of the area represented in Figure 8.1. One of these, collected by Keith Briggs, a Summer Institute of Linguistics worker, from among the Kaluli people near Mt Bosavi, suggested the tephra was so thick it was 'up to the eaves on houses six feet off the ground' (Blong 1982: 101). Another series of accounts from the same language group and located only a few kilometres distant from the first group, was collected by the anthropologists Buck Schieffelin and Steve Feld in the same year (1977). These accounts say the fall of sand was not thick enough to form a layer, but just filled the nodes between the leaves on plants.

Inferences or statements about the duration of the darkness or the duration of the tephra fall are contained in 37 of the accounts. Thirty-one of these estimate the duration as four days or less, with 3-4 days the most common answer. Four accounts suggest that darkness or tephra fall lasted longer than two weeks, with two accounts stretching the period to at least three months.

Thin tephra falls are those less than $100 \mathrm{~mm}$ in thickness. The density of freshly fallen tephra is quite low but it is also highly variable, compacting to a bulk density of around 1.3 to $1.8 \mathrm{~g} / \mathrm{cm}^{3}$. These changes in density with compaction also imply a change in thickness. A reasonable rule of thumb is that thickness on the ground halves with time. If rainfall occurs, compaction is likely to be rapid. We can assume that in areas like the PNG highlands, most compaction occurs within a few days of deposition.

Rainfall washes ash particles off leaves and other surfaces, moving them closer to the ground, thereby representing initial reworking of the volcanic ash. Often, the ash surface forms a semiimpermeable layer that encourages runoff and erosion of the ash. Thus, even when ash falls as a continuous layer of even thickness, it is likely to be quickly altered to form a discontinuous layer of uneven depth within days.

Figure 7.3 shows the compacted (present-day) thickness of Tibito Tephra based on both field measurements and theoretical considerations. Compacted thicknesses in coastal Madang are more than $100 \mathrm{~mm}$, thinning westward to less than $20 \mathrm{~mm}$ around Tari. Given that the freshly fallen thicknesses are likely to have been about twice these values, that tephra drifts in the wind against obstructions, and that it can be quickly eroded and redeposited, most of the legends provide reasonable estimates of thickness. Perusal of the European literature on tephra fall thickness suggests that the taim tudak legends are as accurate in this respect as written accounts from Alaska, Indonesia, the Philippines, the Caribbean and elsewhere (Blong 1984). 
In the upper Wahgi Valley, the median particle size of Tibito Tephra is fine sand in the range 0.1 to $0.15 \mathrm{~mm}$ diameter. The available analyses underestimate the proportion of finer particles, but descriptions in the legends that suggest 'dust' or 'sand' are fairly accurate. Conversely, the available particle size analyses indicate that the largest fraction of Tibito Tephra that fell over mainland PNG was less than $2 \mathrm{~mm}$ in diameter (Blong 1982). Thus, accounts suggesting that stones or trees fell from the sky appear exaggerated. Reference to 'stones' may only indicate problems in translation from local languages or confusion of the taim tudak legend with falls of hailstones, while 'falling trees' could refer to limbs broken from trees by the weight of tephra (see Table 8.1).

Table 8.1 Effects of tephra falls on crops.

\begin{tabular}{|l|l|}
\hline Tephra fall thickness & Effects on crops \\
\hline$<10 \mathrm{~mm}$ & burnt leaves; minor damage to corn and hay; strawberry plants flattened, increasing fruit rot \\
\hline $10 \mathrm{~mm}$ & $\begin{array}{l}\text { hay crop less because of prostration; banana, wheat, mulberry, tobacco and vegetable crops } \\
\text { flattened; scarring of blueberries; breadfruit, apples, cotton dropped }\end{array}$ \\
\hline $15 \mathrm{~mm}$ & hay windrowed before tephra fall unusable \\
\hline $20 \mathrm{~mm}$ & $\begin{array}{l}30 \% \text { loss of lentils; loss of wheat, barley, peas, grass seed; mandarins, mulberry crop } \\
\text { and vegetables considerably damaged }\end{array}$ \\
\hline $25 \mathrm{~mm}$ & $\begin{array}{l}\text { damage to sweet potatoes, yams and tannias; sugarcane prostrated in patches; branches } \\
\text { broken off young breadfruit trees }\end{array}$ \\
\hline $30 \mathrm{~mm}$ & some plants unable to push through tephra crust \\
\hline $40 \mathrm{~mm}$ & $50 \%$ loss of lentils; 15-30\% loss of wheat, spring barley, peas and hay \\
\hline $50 \mathrm{~mm}$ & banana plants damaged; 'forced ripening' of some crops \\
\hline $100 \mathrm{~mm}$ & some branches break under tephra load; palm fronds broken \\
\hline
\end{tabular}

Source: Based on Blong (1984) and Dale, Delgado-Acevedo and MacMahon (2005).

Examination of the rather sparse literature on the duration of darkness and tephra falls suggests a mean rate of tephra accumulation on the ground of 4-5 mm/hour. Blong (1982: 144-145, Fig. 55) displays the relationship between uncompacted thickness of tephra and the duration of darkness, the standard deviation from this relationship and the quality of the darkness reported in the taim tudak legends. The plot suggests that the duration of the tephra fall/darkness is exaggerated in almost all accounts. At Kuk, for example, where Tibito Tephra is $<50 \mathrm{~mm}$ compacted thickness, darkness probably lasted less than 24 hours (assuming compacted thickness is half the original thickness). Even if we assume that Tibito Tephra fell at only half the 'average' rate, the duration of darkness would still have been substantially less than two days.

\section{Effects on plants}

That nearly all of the taim tudak accounts describe deleterious effects on crops is hardly surprising given the central role of subsistence agriculture in the highlands economy. Most accounts mention that leaves were burnt or spoiled, leaves were stripped or tubers rotted (Blong 1979b, 1982). Many accounts describe more than one of these effects. A Huli version mentions that all leaves on trees were dried/burnt and fell off, though there was no permanent damage (Blong 1982: Table 19). Leaves on sweet potato (Ipomoea batatas), sugarcane (Saccharum officinarum), bananas (Musa spp.), dryland and wetland grasses and the like were burnt brown. It was not possible to eat sweet potato because of the taste, leading to famine. However, most accounts are less specific. A few versions of the story emphasise, not the destruction, but the fertilising effect of the tephra fall (see the section on 'Longer-term impacts' below).

Examination of the literature on the effects of tephra falls on plants indicates that four major factors are important: the thickness of tephra falls, the physiognomy of the plants, the season in which tephra fall occurs and the aerosols attached to the tephra. 


\section{The thickness of tephra falls}

Table 8.1 sets out a range of reported effects on crops for tephra falls of compacted thicknesses (though this is not always specified in the original accounts). Although only some of the crops listed are tropical, the wide variety of effects provides insights into potential consequences and indicates how little we know about specific plant responses to tephra fall. It is also clear that many of the types of effects described in the table are similar to those reported in the legends.

\section{The physiognomy of the plants}

Plant physiognomy is an important influence on plant response. For example, the growth position of crops is of obvious importance: crops that grow close to the ground, like strawberries, are more likely to be adversely affected by even thin tephra falls than those that grow on trees. Similarly, hairy leaves and fruits retain tephra and experience reduced photosynthesis, while smooth leaves and fruits are more likely to shed tephra during windy or rainy periods.

The crop production of some plants may be adversely affected by even a small loss of flowers. Others, for example cocoa, can experience more than 90 per cent destruction of flowers without a marked effect on fruit/pod production (Blong and Aislabie 1988). Alternatively, even a reduction in the number of fruit may still result in a larger crop (fewer but larger fruit).

\section{The season in which tephra fall occurs}

Seasonality of tephra fall is obviously important in terms of crop growing season. Tephra fall can promote flower drop or prevent pollination. Young plants may be particularly susceptible to tephra fall. Seasonality of tephra fall may also be important where there are marked wet and dry seasons. In dry seasons, fine tephra blows readily in the wind, forming small drifts with the minute angular glassy fragments abrading delicate plant stems and foliage. Periods of heavy rain, on the other hand, will wash foliage clean, limiting damage from reduced photosynthesis and acid aerosols, but perhaps exacerbating consequences downstream through tephra deposition and plant burial or increased stream turbidity.

\section{The aerosols attached to the tephra}

Aerosols and acid rains are commonly attached to tephra particles. Aerosols may be an important influence on plant growth and survival even in areas where tephra falls are very limited. Coatings on particles may have a $\mathrm{pH}$ as low as 4.0, or even less, producing burning of foliage, blossom drop or poor fruiting. Burnt leaves may have a limited effect or may lead to rotting of tubers and fruit. The amount and frequency of rainfall, and the humidity, may limit or exacerbate the effects of acid aerosols.

Despite the chemically inert glassy silica that makes up the bulk of tephra falls at distances greater than tens of kilometres from the source volcano, trace elements in the glass and in the attached aerosols are likely to include sulphur and potassium, which act as natural fertilisers. On the other hand, elements present in trace amounts might include arsenic, cadmium, copper and molybdenum, which can have deleterious effects on plants at specific growth stages.

Thus, without any analysis of specific versions of the legend, it is clear that the general descriptions of ruined gardens, the burning, stripping or spoiling of leaves and the rotting of tubers in the ground are in accord with the sorts of evidence produced in European accounts of tephra falls around the world (Blong 1984; Dale, Delgado-Acevedo and MacMahon 2005). 


\section{Effects on birds, animals and insects}

Many of the taim tudak stories report effects on animals and birds. An account from amongst the Daribi, near Karimui in Simbu Province, notes that domestic pigs and cassowaries had their bristles or feathers so full of ash that they could not move, while wild pigs were unable to run away and men killed many of them (Blong 1982: Table 20). Pigs and cassowaries that slept under fallen trees or in holes escaped. Many accounts draw distinctions between domestic animals, which were in the houses and escaped relatively unharmed, and wild animals and birds that died or were bewildered, easily caught and eaten as food.

There is an amazing variety of consequences of tephra fall reported in the literature, mainly because there is an amazing variety of animals and insects. Some ashfalls have had marked adverse effects on crickets, cockroaches, flies, grasshoppers, honeybees and other pollinators. Tephra can be abrasive to insect cuticles, even after only a few hours of exposure (Edwards 2005). Animals can be adversely affected by loss of grazing habitat, tephra-caused increase in tooth wear, eye problems, ingestion or inhalation of ash or poisoning by acids attached to particles (Vanderhoek and Nelson 2007).

However, seasonality of the tephra fall is likely to be an important influence. Earthworms, other insects and even animals that spend time below ground level (or hibernating) may be little affected by many tephra falls. But the dominant control on animal and insect survival may well depend most on the survival or disappearance of insects and animals higher and lower in the food chain. Similarly, the effects of tephra falls on plants may disrupt the feeding patterns of some animals and insects but not others.

The size of the area affected by tephra fall may also be important. Exterminated species of birds or animals may be replaced by recolonisation within a few months or years if food becomes available, while the habitat redevelops if the affected areas are limited.

Again, the general effects on birds and animals recorded in most of the taim tudak legends are in good accord with the general comments in the literature for relatively thin tephra falls (Blong 1984). In most cases, this aspect of the legends has an air of veracity and is relatively free from exaggeration, so far as can be told.

\section{Effects on buildings}

About 24 of the taim tudak legends collected refer to the effects on houses (Blong 1982: Table 18); about a quarter of these specifically state that houses were not affected by the ashfall. The others refer to the collapse of houses (sometimes many houses, sometimes a few) or to the deformation or collapse of the roof. More than one quarter of the accounts refer to bumping the roof or cleaning the roof to dislodge the tephra. A few indicate that such action would be taken the next time a tephra fall occurred.

At first glance, one might be surprised that a fall of less than $100 \mathrm{~mm}$ of tephra can cause the collapse of house roofs, but the legends are essentially in accord with the experience reported in the literature (Blong 1982). Even modern buildings can collapse under quite thin loads of wet ash; for example, it was noted around Vesuvius after the 1906 eruption that $100 \mathrm{~mm}$ of tephra fall was sufficient to collapse some flat roofs, though steeper roofs were usually less damaged (Perret 1950). Thatch roofs may be more susceptible than, for example, metal roofs, as the lower angles of sliding friction on the latter aid tephra removal. Certainly, the roofs that are most likely to collapse are those with large spans and those on older buildings where the supporting structure 
may be weaker. The various structural components of a timber building are quite variable in their ability to carry loads, as the strength of timber beams is not consistent (compared with, say, that of steel girders); the failure of one key component can lead to the collapse of the entire building.

While there is little pattern in the legends that suggests roof damage was concentrated where tephra falls were thicker, it is worth noting that none of the accounts from Enga describe roof or building collapse. As the taim tudak story has been intensively investigated in Enga by Mai (1981), we can probably conclude that houses did not collapse in this area. As $20-30 \mathrm{~mm}$ of (compacted) tephra fell across Enga and as similar amounts produced reports of house collapse elsewhere in the highlands, it is intriguing to speculate that Enga houses were more strongly built or that the roofs had shorter spans than elsewhere.

\section{Effects on human health}

Of the 56 versions of the taim tudak considered here, a little over half make no mention of human deaths as a result of the fall of Tibito Tephra (Blong 1982: Table 21). As this would be a most surprising omission, we can be reasonably confident that no deaths resulted from the tephra fall in those areas for which deaths are not mentioned. A further 11 accounts specifically mention that no human deaths occurred. The remaining versions report deaths during the fall as a result of collapsing houses or falling stones or afterwards as a result of hunger. Only two accounts, one from amongst the Melpa (see the version given at the beginning of this chapter) and one from the upper Wage in western Enga, suggest that few people survived the tephra fall and its aftermath. Notably, not one of the accounts collected refers to human injuries as distinct from deaths.

Tephra falls are not the most deadly of volcanic phenomena. However, there are numerous cases of deaths and injuries resulting from roof collapse following thin tephra falls. It is rarely possible to determine the number of deaths as a proportion of the population at risk, but it appears to be usually small unless a large proportion of the populace has gathered in a large structurally weak building (such as an old church) where the roof collapses.

Reports of famine and food shortages are common in the aftermath of large eruptions, but it is not clear that starvation occurs often where tephra falls are thin. Perhaps sweet potato and other tubers are particularly susceptible to rotting or disease resulting from tephra fall—we simply do not know.

Despite these shortcomings in our knowledge, most of the taim tudak accounts can be regarded as reasonably accurate in that few deaths are reported and significant food shortages are not often mentioned. The modern literature concerned with the consequences of thin tephra falls is focused on respiratory problems, usually relatively minor psychological issues and the possibility of longer-term effects including pneumonosilicosis and fluorosis (Baxter and Horwell 2015).

\section{Dating the Time of Darkness}

Many of the taim tudak accounts provide information that can be used to estimate when the fall of tephra occurred. Usually the information refers to an ancestor in whose lifetime the event took place. A date for the event is then estimated allowing, say, 30 years for each generation.

The most consistent estimates come from Mai's (1981) work in Enga, which cluster around the mid-19th century. Estimates from accounts elsewhere group around the mid to late 19th century, but also extend to as early as AD 1700 (Blong 1982). Estimates based on the legends from Long Island suggest the eruption occurred in the range AD 1810-1840.

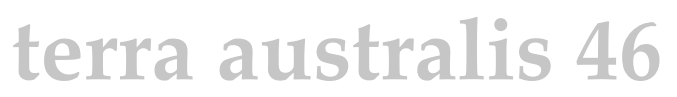


Blong (1982) examined several additional lines of evidence:

- radiocarbon dates on wood and peat samples from Kuk, from other highlands sites and from Long Island;

- lead-210 dates from highlands lake sediments;

- palaeomagnetic secular variation in lake sediments;

- Dampier's AD 1700 sighting and description of Long Island and subsequent reports by other European navigators; and

- the likely time necessary for recolonisation and revegetation of Long Island (20-30 years) after the eruption.

After weighing the evidence, Blong (1982: 193-194) concluded that the radiocarbon ages provided the soundest evidence and that a mid-17th-century date (between AD 1630 and 1670) was the most likely for the eruption of Long Island, the emplacement of Tibito Tephra and the origin of the taim tudak legends.

More recently, the detailed work of Thornton $(1996,2000)$ on the revegetation of Krakatau following the 1883 eruption suggests, if Krakatau is a suitable analogue for Long Island, that an allowance for recolonisation of 40-50 years is more appropriate than 20-30 years.

The original analysis relied on the Stuiver (1978) calibration for translating radiocarbon dates into calendar years. Haberle (1998a) used the revised calibration curve of Stuiver and Reimer (1993) on five highlands samples to show that a date between AD 1645-1680 had a probability of 45 per cent, between $1755-1805$ a probability of 38 per cent and between 1935-1950 a probability of 17 per cent. In 2001, Caspar Ammann (pers. comm.) applied the CALIB 4.3 of Stuiver et al. (1998) to the same five samples, producing new estimates of between AD 1646-1668 (probability 65 per cent) and between 1781-1796 (35 per cent). Using nine samples from the highlands and Long Island produced calendar year ages between 1636-1675 (probability 58 per cent), and between 1776-1801 (31 per cent). Haberle's (1998a: 3) comment still stands: 'while the somewhat later possibility in the eighteenth century cannot be totally dismissed, the weight of independent evidence points to the seventeenth century $\mathrm{AD}$ range'.

Two additional lines of evidence have also become available. The first is that large volcanic eruptions push huge quantities of sulphur and chlorine gases into the upper atmosphere. The sulphur dioxide reacts with water in the stratosphere to form sulphuric acid, some of which is eventually deposited on the Greenland and Antarctic ice sheets where its presence can be detected as a spike of electrical conductivity (Bradley 1999). Hammer, Clausen and Dansgaard (1980) showed there is a marked spike in a Greenland core for the years 1666 and 1667 that could not be assigned to any known eruption. As reported earlier, the 17th-century Long Island eruption is one of the 10 greatest eruptions of the last millennium; thus it should be represented in the Greenland ice core.

The second line of evidence stems from the tree ring density chronologies that record year by year temperature changes in the northern boreal forest zone. Briffa et al. (1998) first made the connection between the anomalously cold years of 1666 and 1667 and the eruption of Long Island. Reference to the boreal forest temperature curve shows that AD 1666 had the 12th largest negative temperature anomaly in the last 600 years.

The Greenland ice core and the tree ring temperature curve are not in themselves evidence that the Long Island eruption occurred in $\mathrm{AD} 1665$ or 1666, which allows up to a year after the eruption for the effects to be registered in ice cores and tree rings. However, we know that such a large eruption would have produced substantial effects. If this was not in 1665 or 1666, then it is necessary to find other unassigned years for the Long Island eruption. As no other unassigned 
years exist, the most economical hypothesis is that the Long Island eruption, the emplacement of Tibito Tephra and the birth of the taim tudak legends all occurred in 1665 or 1666 . We should recognise, however, that there remains some possibility that this hypothesis is incorrect. Until further analysis becomes available, it is preferable to say that the Long Island eruption occurred 'probably in the decade of the $\mathrm{AD} 1660 \mathrm{~s}$ '.

\section{Longer-term impacts}

Amongst people belonging to a number of language groups in Southern Highlands Province, but particularly among the Huli, there seems to be a strong belief that the taim tudak will occur again. All of the language groups in question are more or less adjacent and there may be an element of diffusion as a result. Glasse $(1963,1965)$ reports that the Huli at Tari have made at least two ritual attempts to encourage the recurrence of what is called bingi, because they regard the fall of tephra as beneficial. Similarly, the Enga groups where Mai (1981) recorded the taim tudak story see the tephra fall as culturally beneficial, responsible for an increase in the complexity of tribal dances, the broader spread of pig exchange and technological improvements in fences and housing styles. However, attempts to bring about a recurrence of the ashfall have not been reported in Enga; in fact, the Mae Enga used to make placatory offerings to their ancestors in the hope of ensuring that such untoward events would not recur (Meggitt 1973).

It is also instructive to ask how different things would have been for the various peoples affected by the tephra fall and the taim tudak had they not occurred. We have no complete answer, but it seems likely that the millenarian cult manifest among the Ipili in the 1940s would not have had an emphasis on the coming of a great darkness, with spells to invoke the help of the sun to disperse the cloud of darkness (Meggit 1973). Similarly, the Kilibob-Manup myth among the Yabob south of Madang might not have included the prophecy of a fall of ash that would destroy the gardens and lead to war and cannibalism (Lawrence 1964). The Huli would have been without an important part of their highly structured ritual and the Paiela cycle of world renewal after tephra fall would have been different (Aletta Biersack, pers. comm., 1978). The preparations made by some eastern highlands groups for a 1962 solar eclipse following the warnings of five minutes of darkness by patrol officers (Du Toit 1969) would surely have been less elaborate.

While the suggested connections between the 17th-century eruption of Long Island, the taim tudak stories and belief and behaviour among recent populations are plausible, it is more difficult to establish cause and effect. We know little enough about the direct effects of ashfall on communities and even less about the extent to which environment, culture and people were susceptible or amenable to changes induced by the event. As Grattan, Michnowicz and Rabartin (2007: 172) note, 'mere coincidence is not enough'.

\section{Soil replenishment}

Volcanic soils are commonly regarded as extremely fertile (Mohr and van Baren 1954), especially on islands such as Java where dense populations live on the slopes of numerous active volcanoes. A large number of accounts describe the fertilising effects of falls of volcanic ash, with crops and other plants growing more strongly in the aftermath of an ashfall (see Blong 1984: 348-350). The Huli account of bingi would seem to support this view. But we should note that the fertilising effect is likely to be mixed and vary from nutrient to nutrient, species to species, site to site and across relatively small areas, especially for very thin tephra falls (cf. Cronin et al. 1997). 
Similarly, various authorities have assumed that occasional falls of volcanic ash across the highlands of PNG have had a fertilising effect by replenishing soil nutrients. Hope, Gillieson and Head (1988), for example, suggest that volcanic ashes have produced a macronutrient boost to peat bogs and that a sudden supply of nutrients facilitates increased dominance by particular species for a few generations. This view has been extended to suggest that falls of volcanic ash across the highlands of PNG raised soil fertility, in contrast to the Indonesian part of the island where soil fertility is believed to be lower because the ashfalls did not reach this far (Haberle, Hope and DeFretes 1991).

However, this hypothesis needs to be treated with caution. Many of the accounts of increased plant growth after an ashfall fail to make it clear whether the 'bloom' results from the increased availability of plant nutrients, a decline in competition because some plant species have not fared well, or because insect predators have been decimated by the ash.

Certainly, many ashfalls provide readily available plant nutrients, but we have remarkably little information on how long this increased supply might continue. At Kuk the average interval between now identifiable ashfalls is more than a thousand years-does increased nutrient availability last for all of this period? At Kuk, the total compacted thickness of the thin ash beds in the last 14,000 years or so is probably less than about $220 \mathrm{~mm}$, or about $15 \mathrm{~mm}$ per 1000 years on average. At Tari, the rate of ash accumulation would be about half that. Are these rates of ashfall sufficient to replenish the fertility of soils? Or is soil fertility provided by Tomba Tephra and other massive tephra falls deposited more than 50,000 years ago across enormous areas of the highlands of PNG?

Furthermore, Humphreys (1998) reports that even soils developed on the widespread Chim Formation from which volcanic ash has been removed by erosion are quite fertile. Interestingly, Wood's (2002) investigation of garden ages, using genealogical dating, shows that soil fertility and sweet potato yield decline less on soils adjacent to swamps and on floodplains around Tari after 100 years of cultivation than on volcanic ash soils after fewer than 50 years. Whatever the differences in edaphic factors from site to site, presumably all received roughly the same inputs of thin tephra falls over the last few thousand years as all the sites are a similar distance from the potential source volcanoes.

Different plants and different crops have different nutrient requirements. Sweet potato is generally considered to have a low requirement for available phosphorus, but potassium is recognised as an important sweet potato nutrient (Goodbody and Humphreys 1986). We do not know enough about available nutrients and thin tephras to say which plants would respond best, or for how long, to the falls of volcanic ash that have affected the highlands. Soil replenishment by thin falls of volcanic ash remains nothing more than an interesting hypothesis, albeit one deserving more penetrating investigation.

\section{Additional impacts of tephra fall on a modern society}

What would happen if a tephra fall of up to $100 \mathrm{~mm}$ occurred again across the PNG highlands, covering an area of tens of thousands of square kilometres with fluffy but abrasive volcanic ash and bringing darkness to the region for 24 hours or so? Such a scenario is not unrealistic, as evidenced by the fall of Tibito Tephra and the numerous earlier ashes found at Kuk. At this site and probably across a wide area, we might expect such a fall of tephra every 1000-2000 years on average, with occasional lighter dustings occurring. 
Many of the effects of tephra fall reported in the taim tudak legends would occur again: a few house roofs, on both traditional and western-style houses, would fall in, resulting in some deaths and injuries. Traditional agriculture would suffer, as would the forests and animal life. In some areas electricity, and the lifelines dependent on it, including water supply, sewerage services, storm water drainage and communication systems, would fail. Air transport would be halted for days over a very large area and road transport would be difficult because of the clouds of dust in dry areas and the extremely slippery surface in areas where rain fell. Engines would be damaged where the air filtration systems were not well maintained and many electrical goods, including computers, would be affected, often beyond repair. Even where ashfall is very thin, perhaps only a millimetre, corrosion of exposed metal pipes and roofs might become obvious within a few weeks.

In urban areas, cleanup of the ash and its disposal would be likely to be major problems. For example, a $50 \mathrm{~mm}$ compacted fall of tephra represents about 75,000 tonnes $/ \mathrm{km}^{2}$; finding somewhere to put even a fraction of this mass and the means to transport it is not a trivial task.

\section{Conclusions}

The cataclysmic eruption of Long Island and the fall of Tibito Tephra occurred, most probably, in the AD 1660s. The fall of tephra across more than $85,000 \mathrm{~km}^{2}$ of mainland PNG to a depth of up to $100 \mathrm{~mm}$ gave rise to an amazingly diverse legend about a Time of Darkness when sand fell from the sky, crops were destroyed, some houses collapsed and a few people as well as animals were killed. As far as we know, a version of the taim tudak legend was first written down, nearly 300 years later, in the 1940s (Vicedom and Tischner (1943-48, vol.1: 91). While details, and the emphasis, vary across the highlands and while individual elements in some accounts are undoubtedly embellished, the legends, viewed as a whole, provide a largely accurate version of the likely effects of a fall of up to $100 \mathrm{~mm}$ of ash. While the duration of the darkness or the thickness of the ashfall is commonly exaggerated, and the length of time elapsed since the tephra fall occurred is seriously underestimated, most details are plausible, indeed likely.

The taim tudak legends and the fall of Tibito Tephra are important for a number of reasons:

- the fall of Tibito Tephra was the result of one of the 10 largest volcanic eruptions anywhere in the world in the last thousand years;

- the legends provide the only accounts of the eruption and ashfall;

- they also provide one of the few bodies of information on the effects of tephra fall on a range of subsistence agriculturalists;

- they demonstrate that oral traditions can contain a large amount of reliable information when judged against modern observations;

- the taim tudak accounts prove that essentially accurate oral traditions can be handed down over periods of at least 300 years; and

- the taim tudak provides a chronological marker across a very large area and the only one that predates the arrival of Europeans in the region.

The connection between the taim tudak legend and Tibito Tephra was first raised at Kuk and then substantiated there (Blong 1982). Although we have numerous versions of the legend, there are still opportunities to undertake detailed collection and analysis, similar to the excellent work of Paul Mai and his colleagues in Enga. 
This text is taken from Ten Thousand Years of Cultivation at Kuk Swamp in the Highlands of Papua New Guinea, edited by Jack Golson, Tim Denham, Philip Hughes, Pamela Swadling and John Muke, published 2017 by ANU Press, The Australian National University, Canberra, Australia. 